\title{
Nietzsche, entre o Übermensch e o Unmensch
}

\author{
Danilo Bilate*
}

\begin{abstract}
Resumo: Na Genealogia da moral, Nietzsche define Napoleão Bonaparte como a síntese de Unmensch e Übermensch, isto é, como uma conjunção entre um não-homem, um inumano ou um monstro e um sobre-humano ou um além-do-homem. Investigaremos as observações de Nietzsche sobre o imperador francês, no intuito de esclarecer, por um lado, o conceito de Übermensch e, por outro, o significado do termo Unmensch.
\end{abstract}

Palavras-chave: além-do-homem - não-homem - homem superior Napoleão Bonaparte

Como uma última indicação mostrando o outro caminho, Napoleão aparece, o mais único e mais tardio dos homens, e com ele o problema encarnado do ideal nobre enquanto tal - considere-se que problema é este: Napoleão, esta síntese de não-homem e além-do-homem (GM I 16, KSA 5.288).

"Já houve algum além-do-homem?". Mais do que uma questão que nos anima, era o próprio Nietzsche quem perguntava se haveria alguma correspondência histórica para o que ele nomeou de Übermensch ou além-do-homem (Nachlass/FP 1882-1883, 5[32], KSA 10.227). Conceito pouco explicado por seu criador, deu e ainda dá margens às mais variadas formas de interpretação por parte dos comentadores. Para além das querelas que daí se seguem, podemos

\footnotetext{
* Professor da Universidade Federal Rural do Rio de Janeiro (UFRRJ). Rio de Janeiro, Brasil. Endereço eletrônico: danilobilate@yahoo.com.br.
} 
Bilate, D.

notar que a correlação efetiva entre o conceito com indivíduos históricos concretos é não apenas viável, mas demarcada por Nietzsche frequentemente. Em uma carta à Malwida von Meysenbug de 20 de outubro de 1888, por exemplo, ele desautoriza a antiga amiga a tratar do seu "conceito de além-do-homem", pois "todo leitor sério" dos seus livros "deve saber que o tipo de homem que não [lhe] inspira nojo é precisamente o tipo oposto aos ídolos ideais de outrora, um tipo cem vezes mais similar ao de César Borgia que ao de Cristo". Ao apontar os motivos pelos quais sua amiga teria corrompido seu conceito, Nietzsche a corrige lembrando de um tipo de homens que não lhe inspira nojo, tipo mais parecido com César Borgia do que com Cristo, isto é, similar a ambos, embora com maior proximidade ao primeiro.

A palavra Übermensch aparece pela primeira vez na obra nietzschiana em Assim falava Zaratustra, sendo repetida desde o prólogo até a quarta parte. Ensinamento prometido por Zaratustra durante sua primeira descida ao povo, o além-do-homem surge como uma nova possibilidade de configuração humana diante do tipo de homem vigente, pois "o homem é alguma coisa que deve ser superada" (Za/ZA I Prólogo de Zaratustra 3, KSA 4.14). Tal possibilidade determina o lado positivo do nojo pelo homem, já que somente a partir da experiência de desprezo pelo tipo de homem decadente, alcança-se a condição para se aspirar a um novo tipo humano. Essa experiência é, então, "o maior momento" que poderíamos viver, "a hora do grande nojo" (Za/ZA I Prólogo de Zaratustra 3 , KSA 4.15). O caráter relativo da superação do homem é, assim, admitido. Zaratustra não teria escondido que o tipo que ele valoriza é "relativamente sobre-humano", na medida em que é "sobre-humano em comparação com os bons" (EH/EH, Por que sou um destino, 5, KSA 6.370). Essa posição não difere da que Nietzsche defendeu já no quinto livro da Gaia ciência, quando ele escreveu que o ideal de um espírito "humano-sobre-humano [menschlich-übermenschlichen], que parecerá bem frequentemente inumano [unmenschlich]", por oposição extrema ao tipo de homem até aqui 
existente, se divertiria com o que "até aqui se chamou santo, bom, intocável, divino" (FW/GC 382, KSA 3.637). Ora, a grande saúde associada a esse tipo humano na Gaia ciência é considerada em 1888 como a "condição fisiológica de existência" de Zaratustra (EH/EH, Assim falou Zaratustra, 2, KSA 6.337). Seria a personagem inventada por Nietzsche o modelo de homem que ele visava pela alcunha de além-do-homem?

Ninguém pode responder a essa questão com a certeza que nossa curiosidade anseia, pois isso implicaria usar como instrumento um conceito que nos é ainda confuso e sempre será, dado que o seu criador não o explicitou o suficiente para que o usássemos com segurança. Talvez essa falta de garantia teórica se deva, em verdade, ao estatuto mesmo do conceito de Übermensch. Com efeito, ele é apresentado na maioria das vezes como uma meta ou um fim, que como toda meta ou fim está condicionado ao futuro, em uma palavra, como um porvir. É a meta da "sede de criador", na medida em que essa sede é descrita como "flecha e desejo do além-do-homem" (Za/ZA I Do casamento e dos filhos, KSA 4.92). E se "o que é grande no homem é que ele é uma ponte e não um fim", conclui-se que "o que se pode amar no homem é que ele é uma transição" (Za/ZA I Prólogo de Zaratustra 4, KSA 4.16-17). Se nós tomamos essa afirmação a sério, o além-do-homem deve ser necessariamente entendido como um eterno porvir, porque o homem será sempre uma possível transição para um novo tipo. É claro que, segundo essa hipótese, é impossível procurar exemplos históricos do Übermensch. Por conseguinte, a declaração de Zaratustra que se segue deveria, então, ser considerada um truísmo: "Não há jamais existido o além-do-homem. Eu vi nus o maior dos homens e o menor. Eles são ainda muito semelhantes. Em verdade, mesmo o maior, eu o achei ainda - demasiado humano" (Za/ZA II Dos sacerdotes, KSA 4.119). Todavia, Nietzsche associa diretamente a palavra Übermensch a duas figuras históricas: além de César Bórgia, ele cita Napoleão Bonaparte. Mas, ao longo da obra nietzschiana, o nome de Bórgia é citado apenas sete vezes, 
Bilate, D.

sem jamais uma única explicação do motivo pelo qual ele poderia ser considerado um além-do-homem. O nome de Napoleão, ao contrário, é citado várias vezes durante toda a vida produtiva de Nietzsche, sobretudo a partir de 1880.

Napoleão é descrito na Genealogia da moral como uma síntese de não-homem ou inumano, desumano, monstro (Unmensch) e além-do-homem, descrição muito próxima a do indivíduo dotado de grande saúde na Gaia ciência. Se a aproximação entre Übermensch e Unmensch é feita nas duas ocasiões de maneira explícita, isso não ocorre sempre com outras expressões que os comentadores insistem em associar ao além-do-homem sem quaisquer ressalvas. Em seu importante trabalho sobre o conceito, Wotling, por exemplo, tenta associá-lo ao "tipo supremo" (der höchste Typus), ao "homem supremo" (der höchste Mensch) ou ao "homem superior" (der höhere Mensch), que corresponderiam ao "ideal clássico" (das klassische Ideal), expressões encontradas em alguns fragmentos póstumos e, raramente, em obras publicadas (Wotling cita os fragmentos 27[59] de 1884 e 11[138] de 1887-1888). Para o comentador, a questão central em todos os usos será sempre a do "sucesso fisiológico, isto é, da saúde a da potência dos instintos" do indivíduo". É por isso que Wotling fala também de Shakespeare e de Goethe como exemplos dados por Nietzsche para esse tipo de homem forte e poderoso. Mas Wotling afirma que eles constituem "antes prefigurações, modelos na falta de um melhor, que exemplos de além-do-homem"2, o que é muito provavelmente correto.

Ora, Nietzsche mesmo não associa nunca os nomes de Shakespeare e Goethe com o termo Übermensch e isso indica que Bórgia e Napoleão teriam características inexistentes nos outros. Acreditamos que isso se explica pelo fato de que o tipo clássico é ainda o de um homem incompleto. Com efeito, num fragmento de 1887-1888,

1 WOTLING, P. Nietzsche et le problème de la civilisation. Paris: PUF, 1995, p.348.

2 Ibid., p.352.

218 I Cad. Nietzsche, São Paulo, n. 34 - vol. I, p. 215-229, 2014. 
aliás citado por Wotling, Nietzsche fala do gosto clássico como característica de uma raça soberana e afirma que esse gosto equivale à "vontade de simplificação, de fortalecimento, de manifestação de felicidade, de fecundidade, à coragem pela nudez psicológica" (Nachlass/FP 1887-1888, 11[31], KSA 13.18). Trata-se de valorizar um tipo de homem muito forte como criador, mas no sentido estrito de uma criação intelectual. Wotling mostra que no caso de Napoleão, Nietzsche valoriza também o fato de que ele sabia "se ultrapassar, dominando seus instintos" e que ele tinha sido "funda-

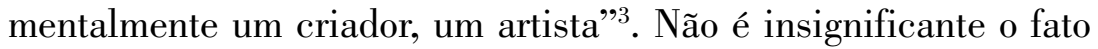
de Nietzsche ter afirmado que Napoleão é um "complemento" de Goethe e que este só fez conceber o "homem mais integral" (Nachlass/FP 1887, 9[179], KSA 12.443-444) e que, ressalte-se, não teria sido ele mesmo esse homem. Com efeito, Nietzsche leu as Conversações de Eckermann e copiou no $\$ 18$ de $O$ nascimento $d a$ tragédia uma parte dessa tão importante observação goethiana: "Napoleão foi um dos homens mais fecundos que existiram. Sim, sim, meu amigo, não é apenas fazendo poesias e peças de teatro que se é fecundo; há também uma fecundidade das ações que em muitas circunstâncias é a primeira de todas". E é Goethe mesmo quem nos explica do que se trata aqui: "Para mim, eu amo um gênio bem constituído também de corpo. - Quando se diz de Napoleão que ele era um homem de granito, a palavra era justa, sobretudo em relação a seu corpo. O que não foi exigido e pôde se exigir dele!", e Goethe acrescenta: "Pouco sono, pouca comida e, ainda por cima, sempre uma atividade de espírito extrema!"”. A força intelectual de um Goethe ou de um Shakespeare - e poderíamos citar muitos outros criadores que Nietzsche estimava, como Stendhal ou Dostoïevski - não seria suficiente para lhes garantir a classificação de

3 Ibid., p.350.

4 GOETHE, W. Conversations de Goethe pendant les dernières années de sa vie: 1822-1832, Paris G. Charpentier, 1863, tomo 2, p.3.

5 Ibid., p.5. 
Bilate, D.

além-do-homem, porque a eles faltaria essa força puramente física que se efetiva concretamente como ação.

O criador intelectual, literato, poeta, pintor, compositor, que Wotling associa indevidamente ao além-do-homem, é aquele que apenas vislumbra o ideal clássico em suas criações artísticas. Mas a única vez em que Nietzsche escreve "ideal clássico" no mesmo local que "além-do-homem" é justamente na famosa caracterização de Napoleão como síntese do não-homem e além-do-homem, no §16 da primeira dissertação da Genealogia. Napoleão surge, então, como a concretização do ideal clássico "corporalmente" e Nietzsche sublinha essa condição: "das antike Ideal selbst trat l e $\mathrm{i} b \mathrm{~h}$ a f $\mathrm{t}$ und mit unerhörter Pracht vor Auge und Gewissen der Menschheit". Não se trata apenas do domínio de si que conquista a independência pela vontade individual, mas trata-se de um corpo poderoso em todos os aspectos, isto é, fisiopsicologicamente. E mais do que uma simples força corporal, o além-do-homem teria a força política necessária para ser, como Napoleão, segundo as palavras de Goethe, "o senhor do mundo" ou "o mestre dos reis". Trata-se da mesma ideia apresentada por Nietzsche - talvez diretamente influenciado por essas expressões goethianas - no seguinte trecho: "A hierarquia seguida num sistema de governo da terra: os senhores da terra enfim, uma nova casta reinante. Nascem dele aqui e lá, semelhante em todos os pontos ao deus de Epicuro, o além-do-homem, a transfiguração da existência" (Nachlass/FP 1885, 35[73], KSA 11.541). Assim, a indiferença de um mestre político em relação às pessoas explica a imagem do "deus espectador epicurista" que Nietzsche coloca em cena por vezes ao falar do além-do-homem (Ver também Nachlass/FP 1885-1886, 2[13], KSA 12.72). Com efeito, Epicuro escreveu a propósito dos deuses, que "abandonados em todas as circunstâncias a suas próprias virtudes, são favoráveis àqueles que lhes parecem e consideram como

6 Ibid., p.173.

220 I Cad. Nietzsche, São Paulo, n. 34 - vol. I, p. 215-229, 2014. 
estranho tudo o que deles difere" ${ }^{\text {" }}$. Mas é provavelmente a essas palavras de Lucrécio, ele que traduziu para os romanos a filosofia epicurista, que Nietzsche faz alusão:

A natureza absoluta dos deuses deve toda ela

Gozar da imortalidade na paz suprema

Afastada, bem longe das coisas de nosso mundo:

Isenta de sofrimento e de perigos,

Forte de suas capacidades, sem nenhuma necessidade de nós,

Ela é insensível aos favores, inacessível à cólera ${ }^{8}$.

Essa imagem de um deus indiferente graças a sua imensa força é a imagem que Nietzsche dá ao além-do-homem. Esse modelo de um indivíduo extremamente poderoso é constantemente definido por Nietzsche também como "homem supremo", ou seja, "aquele que determina os valores e dirige a vontade de milênios pela direção que ele dá às naturezas mais elevadas" (Nachlass/FP 1884, 25[355], KSA 11.106). A indiferença desse indivíduo em relação aos homens do presente se explica pela sua única vontade de criar o porvir da humanidade. Esse amor pelo futuro é o fruto da "abundância prodigiosa" do "homem supremo", esse homem "pródigo até o desperdício" e, por isso mesmo, "indiferente em relação a isso" (Nachlass/FP 1884, 25[140], KSA 11.51). O senhor da terra, que rege a humanidade em função de um fim por ele mesmo estabelecido, indiferente a tudo aquilo que não atrapalha a realização de seu projeto universal. Ele deve estar disposto a desperdiçar até mesmo a vida de seus soldados, como no caso de um chefe militar, exatamente como era Napoleão.

7 EPICURO. Lettre à Ménécée. Paris: GF-Flammarion, 2009, p.45.

8 LUCRÉCIO. De la nature des choses. Extratos disponíveis em Lettre à Ménécée. Op. Cit., p.75. 
Bilate, D.

Napoleão Bonaparte fascinava Nietzsche desde aproximadamente seus dez anos, quando sua avó contava para o neto, com admiração, as histórias das conquistas napoleônicas ${ }^{9}$. Além de suas leituras como das Conversações de Goethe, no início dos anos 1870, e de muitas outras fontes prováveis de informação sobre o imperador francês, Nietzsche se dedica efetivamente, nos anos 1880, à pesquisa textual sobre Bonaparte. Evidência disso é o fato de ele copiar muitas passagens tiradas de textos consagrados total ou parcialmente a Napoleão. A maior parte dessas cópias são retiradas das Mémoires de Madame de Rémusat, das quais ele faz inúmeras anotações durante o outono de 1880. Em seguida, é sem dúvida do artigo Napoléon Bonaparte de Taine, publicado na Revue des deux mondes de 15 de fevereiro de 1887, que Nietzsche copia mais trechos. Tendo se correspondido com Taine, em uma carta de 04 de julho de 1887, Nietzsche agradece pessoalmente pelo referido artigo do historiador, ocasião em que o filósofo novamente considera Napoleão como uma síntese de Übermensch e Unmensch. Embora menos citados, também La France nouvelle de Prévost-Paradol e Vie de Napoléon de Stendhal, são importantes fontes de pesquisa para Nietzsche.

Vários são os aspectos da vida de Napoleão que Nietzsche valoriza, como, para citar apenas um exemplo, o fato de Bonaparte conceber a Europa "como uma unidade política" (Nachlass/FP 1888, 15[68], KSA 13.451). Entretanto, para entendermos o motivo pelo qual ele pode ser concebido como uma síntese de além-do-homem e não-homem, precisamos investigar as suas características fisiopsicológicas. Nesse sentido, Nietzsche declara que Napoleão tinha uma "estrutura simples" e uma "engenhosidade na elaboração e no desenvolvimento de um único motivo ou de um pequeno número de motivos" (M/A 245, KSA 3.203). Provavelmente ao pensar sobre o "único motivo" que movia o imperador, Nietzsche se refere a

9 JANZ, C. Nietzsche: biographie. Tome 1. Paris: Gallimard, 1984, p.50.

222 I Cad. Nietzsche, São Paulo, n. 34 - vol. I, p. 215-229, 2014. 
sua "grande paixão pelo poder" (Nachlass/FP 1880, 4[197], KSA 9.149). Em outros termos, Bonaparte seria capaz de se dominar em função de um único motivo: o poder. Graças a essa simplicidade, Napoleão podia ser honesto consigo mesmo e discernir seus interesses mais fortes sem confundi-los com os outros. Como explica Nietzsche, "ele sabe o que quer e não se ilude sobre si mesmo" (Nachlass/FP 1880, 4[66], KSA 9.115). Lúcido, portanto, Napoleão era também "alegre e sereno", características a ele atribuídas por Madame de Rémusat ${ }^{10}$ que Nietzsche copia em seus cadernos (Nachlass/FP 1880, 6[33], KSA 9.202).

Além disso, Nietzsche anota quatro semelhantes observações que teriam sido feitas pelo próprio Napoleão. Segundo a primeira, o imperador afirmara que "o acaso permanece sempre um mistério para os espíritos medíocres e se torna uma realidade para os homens superiores". Do mesmo modo, ele teria dito que "os medíocres são levados a uma certa evidência pelas circunstâncias que eles não criaram" (Nachlass/FP 1880, 6[42], KSA 9.204) ${ }^{11}$. A superioridade de um homem se efetivaria pelo relativo controle do seu destino, na medida em que o seu fado é criado por si mesmo. Esse relativo controle se daria por uma estratégia de relação com o real, estratégia que pressupõe improviso, cálculo e regência dos afetos. Nesse sentido, Napoleão afirmara: "para ser um verdadeiro grande homem, é preciso realmente ter improvisado uma parte de sua glória e se colocar acima do acontecimento que foi causado" (Nachlass/FP 1880, 6[43], KSA 9.204) ${ }^{12}$. E Nietzsche também copia as seguintes palavras do imperador: "quando os políticos são realmente hábeis, eles sabem se tornar mestres de suas paixões, pois eles calculam seus efeitos" (Nachlass/FP 1880, 6[45], KSA 9.205) ${ }^{13}$. Chama a

10 RÉMUSAT, Mme. Mémoires de Madame de Rémusat. 1802-1808. Paris: Calmann-Lévy, 1906, tomo 1, p.395.

11 Tratam-se de anotações de Rémusat, encontradas no tomo 1, p.333 e p.334 de suas Memórias, respectivamente.

12 Ibid., p.334.

13 Ibid., p.336. 
Bilate, D.

atenção de Nietzsche o fato de o imperador valorizar o indivíduo criador que, como o príncipe maquiaveliano, pode dominar seus próprios afetos e conhecer os efeitos de suas próprias ações, agindo prudentemente com algum grau de estratégia em relação ao acaso. Ora, segundo Madame de Rémusat, antes de pronunciar essas frases copiadas por Nietzsche, Bonaparte explicara:

A ciência militar consiste inicialmente em calcular bem todas as chances e, em seguida, em fazer exatamente, quase matematicamente, a parte do acaso. É sobre esse ponto que não se pode errar e que um décimo a mais ou a menos pode mudar tudo. Ora, esse casamento da ciência e do acaso só pode ocorrer num gênio, pois para isso é preciso sempre criação e, é claro, a maior improvisação do espírito humano é a que dá uma existência ao que não existe ${ }^{14}$.

É por isso que Nietzsche escreveu que Bonaparte faz parte dessa "raça de homens inventivos que experimentam sem cessar e que não titubeiam em banir deles mesmos o acaso" (Nachlass/ FP 1880, 1[99], KSA 9.27). É preciso um alto grau de força para vencer o acaso e para dominá-lo, como se nós não fizéssemos parte do fatum. A lucidez, a alegria, a serenidade e a inventividade de Napoleão se dariam pela sua capacidade de dominar seus próprios afetos e essa característica talvez seja a mais sublinhada por Nietzsche. Segundo ele, o domínio de si em Napoleão é o fruto do orgulho que ele vivenciava, um orgulho que "sente como uma afronta a preponderância de um determinado afeto sobre a atitude geral e a ordem da razão: daí surge o hábito e a vontade de tiranizar o impulso e fazê-lo como que gemer" (M/A 109, KSA 3.97). É, pois, o orgulho do eu que experimenta o prazer ao exercer o poder de governar os outros afetos. Mas o orgulho de Bonaparte não é vaidade. É por isso que Nietzsche anota essas palavras do imperador:

14 Provável fala de Napoleão citada também nas Memórias de Rémusat, tomo 1, p.333.

224 I Cad. Nietzsche, São Paulo, n. 34 - vol. I, p. 215-229, 2014. 
"não há nada de nobre nem de baixo nesse mundo" e "eu sou covarde, essencialmente covarde" e Nietzsche concluí daí que "Napoleão estava acima da honra" (Nachlass/FP 1880-1881, 8[107], KSA 9.405). Trata-se mais uma vez de uma passagem das memórias da Madame de Rémusat, onde ela se reporta às seguintes palavras de Napoleão: "Uma covardia? Ah! O que me importa? Saiba que eu não temeria fazer uma, se ela me fosse útil. No fundo, não há nada de nobre nem de baixo nesse mundo; eu tenho em meu caráter tudo o que pode contribuir para garantir o poder e enganar aqueles que pretendem me conhecer"15. Bonaparte estava acima da honra, pois ele estava acima de qualquer referência de alteridade. Não é, pois, surpreendente que ao falar da "crença nos grandes espíritos superiores e fecundos", crença frequentemente ligada à superstição de que "tais espíritos são de origem sobre-humana", Nietzsche se refira a Napoleão, "de quem o caráter, isto é certo, justamente misturou essa crença nele mesmo e em seu destino com o desprezo pelos homens que daí se seguia, para se elevar a essa unidade poderosa que o distingue de todas as personalidades modernas" (MA I/HH I 164, KSA 2.155-156). Contudo, o desprezo desse homem não pode ser confundido com o ressentimento, pois se trata aqui da indiferença de um deus epicurista. Segundo a lógica do poder, o homem supremo precisa ter um certo grau de indiferença pelos homens e evitar toda forma de compaixão: "Para Napoleão só os instintos essenciais do homem eram levados em consideração e ele tinha o direito de não prestar nenhuma atenção às exceções, por exemplo, à compaixão - com o risco de se enganar aqui e ali" (Nachlass/FP 1885, 34[131], KSA 11.464). É por isso que Nietzsche declara que Bonaparte é um tipo de mistura entre o além-do-homem e o não-homem. Ele é um homem com um "coração indiferente" (Nachlass/ FP 1884, 25[110], KSA 11.41) ${ }^{16}$ e sem compaixão que se afasta da

15 Provável fala de Napoleão novamente citada nas Memórias de Rémusat, tomo 1, p.108.

16 Expressão copiada de PRÉVOST-PARADOL, L-A. La France nouvelle. Paris: Michel Lévy Frères, 1869, p.307. 
Bilate, D.

moral e se situa, por conseguinte, para além do bem e do mal. Tal é o sentido dessa observação de Prévost-Paradol que Nietzsche copia: "verifica-se em Napoleão essa falta de discernimento entre o bem e o mal, essa sede imperiosa de sucesso, essa indiferença absoluta em relação à injustiça dos meios" (Nachlass/FP 1884, 25[110], KSA 11.40) ${ }^{17}$. Com efeito, segundo Nietzsche, Bonaparte é o homem que afirma o "instinto mais poderoso", a saber, "a avidez de dominar" (Nachlass/FP 1887, 10[5], KSA 12.456-457). O imperador aparece como um exemplo extraordinário da afirmação da vontade de poder, sendo sua vida a realização sem limites desse impulso fundamental. Napoleão luta pela efetivação de sua própria força e é indiferente aos outros, salvo se os outros podem ajudá-lo a aumentar o seu poder. Por esse motivo, ele é considerado frequentemente como imoral e dotado de uma crueldade inumana. E tal julgamento seria válido se por "crueldade" nós compreendêssemos simplesmente a "indiferença". Nesse caso, poderíamos classificar Napoleão como um homem cruel. Mas na significação do termo "crueldade" está quase sempre presente um sentimento que está, no entanto, ausente em Bonaparte e é precisamente esse elemento que Nietzsche abomina em certas formas de violência: o ressentimento. Em Napoleão, a violência é apenas uma consequência circunstancial de sua vontade de poder. Essa observação de Madame de Rémusat chama a atenção de Nietzsche, que a traduz da seguinte maneira: "O esforço de $\mathrm{Na}$ poleão tendia ao poder: ele teria preferido a paz se essa lhe tivesse fornecido um acréscimo de poder" (Nachlass/FP 1880, 6[190], KSA $9.246)^{18}$. A declaração seguinte de Bonaparte - que Nietzsche também anota - é sem dúvida ainda mais significativa: "Eu não tenho absolutamente nenhum ódio, eu não sou absolutamente suscetível de nada fazer por vingança: eu afasto simplesmente o que me atrapalha!" (Nachlass/FP 1880, 6[30], KSA 9.200) ${ }^{19}$. Napoleão ignorava

17 Ibid., p.305.

18 RÉMUSAT, Mme. Op. Cit, tomo 2, p.274.

19 Id., tomo 1, p.389. 
o ressentimento, pois ele era um indivíduo forte, fora de toda relação moral de alteridade. $E$ isso porque o egoísmo do qual ele tinha consciência lhe dava a força necessária para afirmar a si mesmo, como atesta essa fala, também copiada por Nietzsche, que o imperador dirigiu a sua esposa: "Eu tenho o direito de responder a todas as suas reclamações com um eterno eu. Eu estou à parte de todo o mundo, eu não aceito as condições de ninguém" (Nachlass/FP 1880-1881, 8[116], KSA 9.407) ${ }^{20}$.

Mas Nietzsche não se satisfaz completamente com a figura de Bonaparte. Durante a primavera e o verão de 1883, Nietzsche ressalta o fato de que Napoleão teria sido corrompido e de que, por isso, ele teria perdido sua "nobreza de caráter" (Nachlass/FP 1883, 7[27], KSA 10.251 e 7[46], KSA 10.257). Além disso, ele chega mesmo a escrever, numa anotação solta, "homens superiores a Napoleão" (Nachlass/FP 1883, 12[49], KSA 10.413). Aos olhos de Nietzsche, ao que parece, portanto, o imperador não seria um modelo perfeito de homem. $\mathrm{O}$ que faltaria a Napoleão para que ele fosse um ideal? Ora, Nietzsche copia de Madame de Rémusat a afirmação de que Bonaparte "ignorava os grandes sentimentos que se sobrepõem à má sorte" (Nachlass/FP 1880, 6[26], KSA 9.199)21. Imediatamente após ter pensado sobre o problema do além-do-homem (Nachlass/FP 1884, 27[58], KSA 11.289) e de ter escrito sobre o homem supremo (Nachlass/FP 1884, 27[59], KSA 11.289), Nietzsche sintetiza um modelo de homem por vir pela tão célebre fórmula: "o César romano com a alma de Cristo" (Nachlass/FP 1884, 27[60], KSA 11.289). Como sabemos, Napoleão se inspirou em César e, de fato, Nietzsche os aproxima várias vezes (Ver, por exemplo, Nachlass/FP 1886, 1[56], KSA 12.24 ou 1884, 25[110], KSA 11.40-41). Mas Nietzsche não relaciona nunca o imperador a Cristo, enquanto representante por excelência do amor. Se, como vimos, ele liga Bórgia a Cristo na

20 Ibid., p.114-115.

21 Ibid., p.384.

Cad. Nietzsche, São Paulo, n. 34 - vol. I, p. 215-229, 2014. 
Bilate, D.

carta à Malwida von Meysenbug de 20 de outubro de 1888, é para ressaltar que o primeiro estaria muito mais próximo do além-do-homem, mas não que o segundo não o estivesse. Seria, então, o amor incondicional ao fatum, experimentado por Cristo, um dos grandes sentimentos que se sobrepõem à má sorte e que faltaria a Napoleão Bonaparte? Definitivamente, a partir dos escritos nietzschianos nós não podemos responder a esta questão.

Considerando que um dos ensinamentos mais importantes de Zaratustra é o amor em suas mais variadas formas, sobretudo como amor fati, nos parece uma hipótese válida que a personagem nietzschiana seja o modelo de Übermensch - ainda que ele não tenha o poder político de um Bonaparte ou de um Bórgia -, ou ainda um complemento imaginário dessas duas figuras históricas. Aos dois faltaria o amor ao destino. Zaratustra, ao contrário, é o representante maior do amor fati, sem viver as fraquezas do amor de Cristo, tais como a compaixão, afeto que está em contradição com a possibilidade de toda elevação de poder de um indivíduo. No lugar da fórmula que propõe um César com a alma de Cristo, poderíamos supor um Napoleão com a alma de Zaratustra.

Apesar de escrever num fragmento do outono de 1887 que "o homem superior é o não-homem e o além-do-homem" e que os dois "se pertencem reciprocamente" (Nachlass/FP 1887, 9[154], KSA 12.426), Nietzsche sempre mantém o conceito de Übermensch sem definições rigorosas que nos possibilitem associá-lo definitivamente ao Unmensch. De todo modo, se Bonaparte não pode ser considerado uma síntese de além-do-homem e não-homem, caso a primeira alcunha a ele não servir, sem dúvida ele é um não-homem ou um monstro, isto é, uma transição entre a forma ordinária de humanidade à algo diferente, transição que se efetiva como negação a todo tipo comum de homem. Como Unmensch, enfim, Napoleão Bonaparte é uma das figuras históricas mais admiradas por Nietzsche. 


\begin{abstract}
On the Genealogy of Morals, Nietzsche defines Napoleon Bonaparte as a synthesis of Unmensch and Übermensch, ie, as a conjunction between a non-man, a monster or an inhuman and superhuman. We will investigate Nietzsche's remarks about the French emperor, to clarify, on the one hand, the concept of Übermensch and, on the other hand, the meaning of the word Unmensch.

Keywords: superhuman - non-human - superior man - Napoleon Bonaparte
\end{abstract}

\title{
referências bibliográficas
}

1. EPICURO. Lettre à Ménécée. Trad. de Pierre-Marie Morel. Paris : GF-Flammarion, 2009.

2. GOETHE, W. Conversations de Goethe pendant les dernières années de sa vie : $1822-$ 1832, recolhidas por Eckermann. Trad. de Émile Delerot, Paris G. Charpentier, 1863. 2 tomos.

3. JANZ, C. Nietzsche : biographie. Tome 1. Paris : Gallimard, 1984.

4. LUCRÉCIO. De la nature des choses. Trad. de J. Kany-Turpin. Extratos disponíveis em Lettre à Ménécée. Op. Cit., 2009.

5. NIETZSCHE, F. Digitale Kritische Gesamtausgabe Werke und Briefe auf der Grundlage der Kritischen Gesamtausgabe Werke, herausgegeben von Giorgio Colli und Mazzino Montinari, Berlin/New York, Walter de Gruyter, 1967ff. und Nietzsche Briefwechsel Kritische Gesamtausgabe, Berlin/New York, Walter de Gruyter, 1975ff., herausgegeben von Paolo D‘Iorio. Acessado em várias datas. Disponível em: http://www.nietzschesource.org/texts/eKGWB

6. NIETZSCHE, F. Euvres philosophiques complètes. Paris : Gallimard, 1968-1997, 18 volumes.

7. PRÉVOST-PARADOL, L-A. La France nouvelle. Paris : Michel Lévy Frères, 1869.

8. RÉMUSAT, Mme. Mémoires de Madame de Rémusat. 1802-1808. 2 tomos. Paris : Calmann-Lévy, 1906.

9. STENDHAL. Vie de Napoléon. Paris : Éditions Payot \& Rivages, 2006.

10. TAINE, H. Napoléon Bonaparte. Revue des Deux Mondes. Volume 79. Terceiro período, de 15 de fevereiro de 1887.

11. WOTLING, P. Nietzsche et le problème de la civilisation. Paris : PUF, 1995.

Artigo recebido em 10/06/2013.

Artigo aceito para publicação em 15/11/2013.

Cad. Nietzsche, São Paulo, n. 34 - vol. I, p. 215-229, 2014. 